\title{
The law, medical students, and assault
}

\author{
Susan Bewley
}

As students most doctors will have performed examinations on anaesthetised patients who have not given explicit consent. Surgeons invited or told the students to participate. It might have been embarrassing to do vaginal examinations under the instructions of the gynaecologist, but did anyone realise that they were laying themselves open to charges of assault? This article discusses the differences between students and doctors with reference to the law about touching patients. Although it has not yet been tested in the courts, a student would have little defence to a charge of assault and might be liable to punitive damages.

Traditionally, medical students have been taught how to do vaginal examinations by examining women who are anaesthetised. Concern has been expressed about this being done without the woman's consent or knowledge. ${ }^{\prime 2}$ Some medical schools have introduced consent procedures, but these are by no means universal. ${ }^{3}$ Although I will be discussing vaginal examination my conclusions are relevant to all specialties where students touch patients.

\section{Moral and legal nature of medical examination}

Doctors touch patients, and during surgery they invade bodies. They do this for the benefit of patients and to fulfil the duty of care.

Every person has a moral right not to be interfered with against his or her will. Touching people against their will is a violation of autonomy. This is recognised in law, and a doctor who touches or invades a person without his or her consent may face charges of battery. ${ }^{4}$ This is defined as the intentional application of force against another person without that person's consent and without a lawful excuse. Battery can be both a crime and a civil wrong for which compensation can be exacted. The important element is lack of consent; the touching does not have to have been hostile, rude, or aggressive. 5

A vaginal examination is no different from any other form of touching. When doctors or students touch patients they must have the requisite consent. The essential distinction is that a vaginal examination performed by a student is for the benefit of the student and future patients but not the patient being examined. If a woman felt aggrieved because a vaginal examination had been performed without her consent she might take legal action using the powerful charge of battery rather than the charge of negligence.

Battery differs from negligence in several important respects. Firstly, a woman does not have to establish that the doctor or student owed her a duty of care. Secondly, no tangible injury has to be established as the injury comprises the uninvited invasion of the body. Thirdly, the burden of proof that consent was obtained lies with the doctor whereas with negligence the patient has to prove the chain of causation - that the doctor's negligent mistake led, through each step of the way, to the harm caused. Finally, exemplary damages can be awarded. ${ }^{6}$ Much of the protection afforded doctors in negligence is absent.
Courts are reluctant to use the charge of battery against doctors who have acted in good faith, ${ }^{7-9}$ but the aim of the law is to protect people from being touched against their will. Negligence, although more familiar to obstetricians and gynaecologists, is largely irrelevant in the case of medical students because they do not owe the same duties of care. Negligence cases take place in the context of diagnosis and treatment, but students do not diagnose or treat.

\section{Consent}

Obtaining consent will protect the doctor from a charge of battery, and it can be express (written or spoken) or implied. Express consent does not mean a signature on a piece of paper; this is not enough to ensure the patient's understanding. ${ }^{8}$ Conversely if a patient understands and agrees to a procedure there is no legal necessity for it to be documented in writing. The consent form serves mainly as an aide memoire. Obtaining the patient's signature before the operation creates a set piece for doctor and patient to communicate with each other, and it is an appropriate time to discuss the possibility of a student performing a vaginal examination.

Consent can also be implied by a patient's conduct or action. If a doctor says, "I would like to examine you," and the patient goes behind a screen and takes off her clothes that is a clear assent; the actions speak as loud as words. ${ }^{10}$ When a patient is being treated by a team implied consent may extend to all members of the team. By entering hospital patients effectively agree to be treated by all the staff involved in their care. It is not necessary for each person to ask repeatedly for consent.

These two aspects of implied consent - the patient's actions implying consent and consent extending to al members of a team-have been used to justify the use of vaginal examination under anaesthesia for teaching students. It has been argued that when a patient attends a teaching hospital she is giving her implied consent to being examined by medical students. This is either because the patient has attended the hospital in the first place or because the medical student is part of the caring team. Both of these arguments are, however, untenable. Firstly, most patients do not choose which hospital to attend, and some may not know what the term teaching hospital means. It might be understood to mean a place for training specialists, foreign postgraduates, or students who are present only as observers. Even if the term is correctly understood by the patient there is still a substantial leap to assuming a willing participation in teaching. If medical students are training in hospitals not designated as teaching hospitals the argument falls completely.

Secondly, medical students are not part of the team caring for the patient. They spend time with the patient, elicit extra details about her medical history and relay anxieties and questions to the doctors in charge of her care. They accompany her to the operating theatre and may then perform an examina-
Hospital, London

Susan Bewley, senior registrar

BMf 1992;304:1551-3 
tion which is identical to part of the operative procedure. But because they are not trained doctors their findings cannot be relied on and the examination is necessarily an optional extra; it is not part of the therapeutic process. The contributions of students are fortuitous and their examinations of no standing so the notion of implied consent is not adequate.

\section{Legally valid consent}

If consent to vaginal examination under anaesthesia cannot be implied what features make consent sufficiently valid to avoid a charge of battery? In law three criteria must be met: capacity, voluntariness, and information.

\section{CAPACITY}

Capacity is defined by an individual's age or level of understanding. Sixteen year olds are presumed to have the capacity to give a valid consent, but mentally impaired adults may not have it and some children under 16 may." If a patient is incompetent, consent may be given by proxy by a parent or guardian, who has to be guided by what is in the patient's best interests. ${ }^{12}$ But can non-therapeutic procedures done for teaching purposes ever be in the best interests of an incompetent patient? It is probably adequate that, if they do no harm, they are not against the interests of the patient. Thus students may, with discretion, learn to perform procedures on patients who are not capable of giving consent. There will still be a difference, however, between a student taking the pulse of a child and performing a vaginal examination on a mentally handicapped adult.

Unconscious patients have also lost the capacity to give their consent or refuse it. Doctors must sometimes operate without express consent on patients brought into hospital unconscious. There are several different legal interpretations as to why such emergency treatment does not constitute battery: firstly, consent might be presumed since the patient would have wished to consent and will wake up grateful; or, secondly, touching without consent is demanded by medical considerations or performed out of necessity..$^{14}$ is There is also the consideration that surgeons should not be inhibited from saving lives by worries about possible future battery charges. ${ }^{14}$ But it does not matter which reason protects surgeons as none of them is applicable to students. It is rare for gynaecology patients to come to hospital unconscious, though a student might be present after a woman had collapsed with a ruptured ectopic pregnancy. In this case, despite the valuable

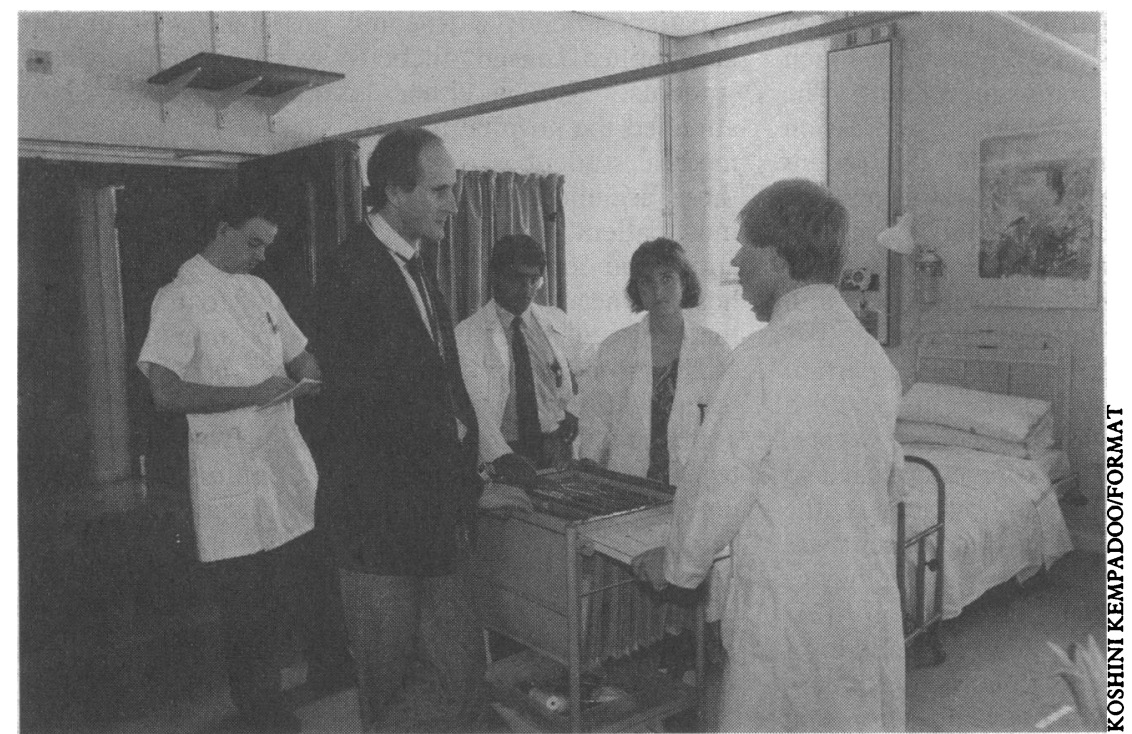

As they are not trained doctors students cannot be considered as part of a caring team for consent purposes lessons to be learnt, none of the defences against battery that are available to doctors apply to a student.

\section{VOLUNTARINESS}

When combining treatment with teaching doctors have dual roles and must guard against conflict between them. If a person acquiesces because she does not realise what is entailed or for fear of the consequences of refusal the courts can find that she did not consent. ${ }^{16}$

Patients may be susceptible to pressure and agree to procedures or research to please their doctor. Offering the patient an earlier operation or money in return for cooperating with the teaching of medical students might be considered as applying pressure.

\section{INFORMATION}

For valid consent a patient has to be "informed in broad terms of the nature of the procedure which is intended." If a woman does not know that a medical student is going to examine her during an operation she cannot consent to it. Two similar pelvic examinations, one for the purposes of the operation (for the benefit of this patient) and one for the purposes of learning (for the benefit of the medical student and future patients), are of different kinds. If the patient is deceived about the real nature of a treatment consent will be invalidated. English law requires that to avoid a charge of battery the patient must understand the general nature of the procedure-that is, that she is being used for teaching.

The fact that vaginal examination under anaesthesia without consent has been practised for many years in other medical schools is no defence. If a medical student was charged with battery for performing a vaginal examination on an unconscious woman without her prior consent the case would be extremely difficult to defend. In addition, students do not belong to medical defence bodies. Judges might be reluctant to condemn a student acting under supervision but they would apply the law.

\section{Need for medical students to learn}

For students to learn the art of examination there must be a continuing source of subjects for teaching. Some doctors fear that asking patients for their consent might lead to refusals to help and thus interfere with training. If this proved to be true, the argument that patients are presently being coerced would be strengthened. If increasing the safeguards did lead to a shortage of willing patients there might be a need to introduce incentives for people to volunteer. Until such time we must be guided by the present law.

Two national studies of the teaching of vaginal examination have been performed: one by the Greater London Association of Community Health Councils in $1987^{1}$; the other by Women in Medicine in $1990 .{ }^{16 a} \mathrm{~A}$ wide variation in practice was found but there was no indication that teaching had suffered in those schools that had adopted more rigorous consent procedures. Several medical schools now insist on signed consent for vaginal examinations in operating theatres while others leave it to the individual student to make a verbal request. Some send patients information about students with appointments and preoperative literature. Recommendations based on the present best practices have been compiled and circulated to al clinical professors by the pressure group, Women in Gynaecology and Obstetrics.

Students are not part of the usual doctor patient equation and need their own rules. We need to recognise the generosity of patients who allow themselves to be used for teaching. Many obtain pleasure in giving something back to the system and understand 


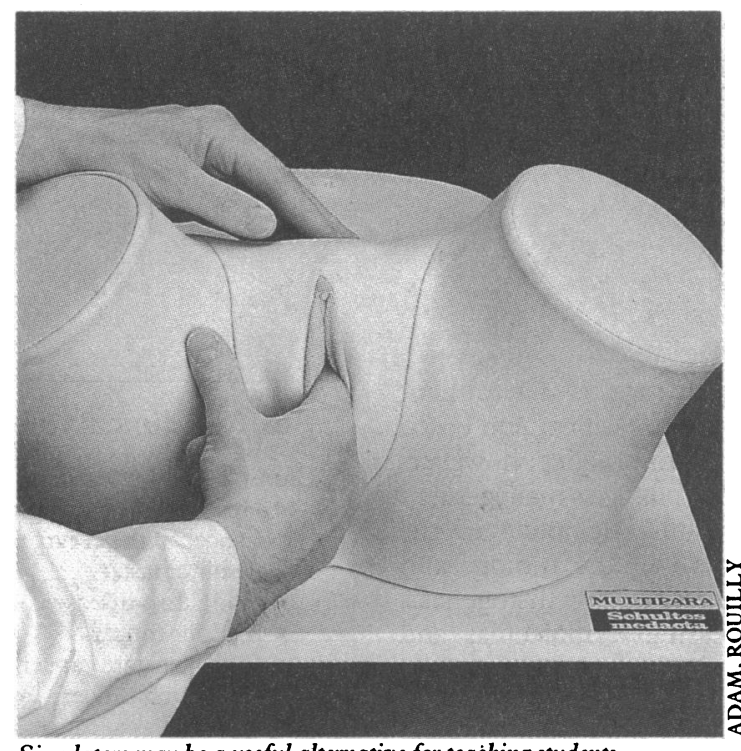

Simulators may be a useful alternative for teaching students

the need to train the next generation. Formalising the criteria for allowing the use of patients as "clinical material" paradoxically enhances their status and shows, to students and patients alike, the great store doctors set by consent.

Although this paper has considered vaginal examination, patients may be vulnerable in other disciplines Many might object to being used without their consent for the teaching of other procedures (for example, rectal, breast, and testicular examinations, intubation, and suturing) while they are anaesthetised. Lessons learnt about vaginal examination might be valuable in other branches of medicine.

\section{Wider implications}

Why has vaginal examination under anaesthesia by medical students become a hot issue? The reason must lie in the intimate nature of the examination of a woman, usually by a man, and the particular concern surrounding the use of women as "guinea pigs." These anxieties have been expressed by female patients, community health councils, medical students, and doctors. ${ }^{17}$ There is also concern that the manner in which students are taught may influence their later attitude to patients. ${ }^{18}$

In many ways obstetricians and gynaecologists are progressive in reviewing their practice. This may be because they have an articulate and largely healthy patient population, but also because a vaginal examination is the most intimate and invasive of examinations and because the dialogue between doctors and patients has changed in parallel with women's emancipation. Consent underpins the doctor-patient relationship and it is perilous to undermine it, even for the laudable aim of teaching. Even if a practice were acceptable in the past, standards must evolve.

\section{Conclusion}

The law is a clumsy instrument by which to control doctors' behaviour. Standards are set by the profession: the General Medical Council, the royal colleges, the British Medical Association, and the defence bodies. Using anaesthetised women for teaching vaginal examinations may have originated from a concern for women's modesty. Women might even have accepted that this was desirable; but they were not asked. To leave individual students to obtain consent is not adequate and may be haphazard. Students are vulnerable and need clear guidance. This guidance has not come spontaneously from the medical schools. The defence bodies, who have the legal expertise, have not involved themselves, maybe in order not to undermine their effectiveness in defending a student who was charged..$^{19}$ If a medical student was accused or convicted of battery strict protocols might then be laid down, but only after hostile media attention had been directed towards gynaecologists. Acrimonious disputes between the medical profession and the public are surely better avoided..$^{20}$ Abiding by the dictates of best practice recommendations when obtaining consent for teaching will protect patients and students and promote good practice for students to emulate.

Simulators for investigation are available from Adam, Rouilly (London) Ltd.

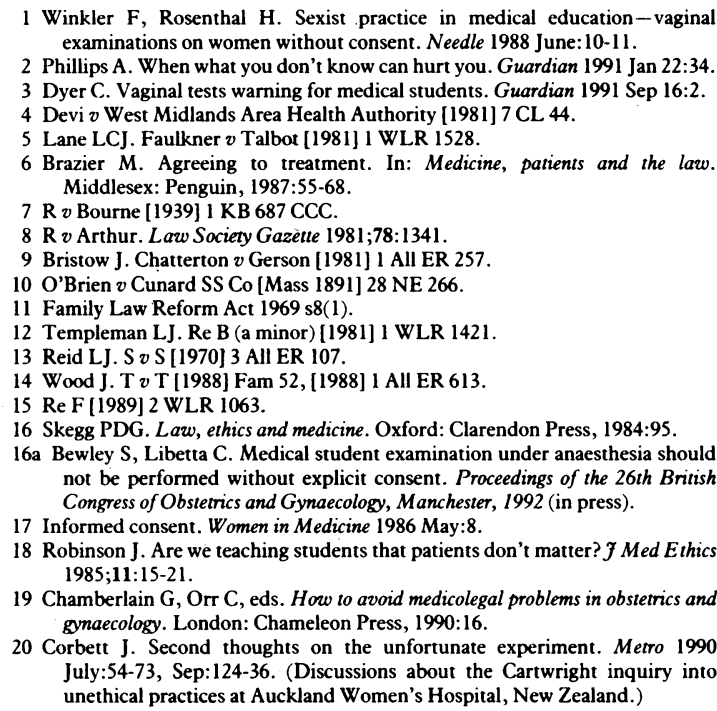

1 Winkler F, Rosenthal $H$. Sexist practice in medical education-vaginal examinations on women without consent. Needle 1988 June: 10-11.

2 Phillips A. When what you don't know can hurt you. Guardian 1991 Jan 22:34.

3 Dyer C. Vaginal tests warning for medical students. Guardian 1991 Sep 16:2.

4 Devi $v$ West Midlands Area Health Authority [1981] 7 CL 44

5 Lane LCJ. Faulkner $v$ Talbot [1981] 1 WLR 1528

6 Brazier M. Agreeing to treatment. In: Medicine, patients and the law. Middlesex: Penguin, 1987:55-68

$7 \mathrm{R} v$ Bourne [1939] 1 KB 687 CCC.

$8 \mathrm{R} v$ Arthur. Law Society Gazette 1981;78:1341.

9 Bristow J. Chatterton $v$ Gerson [1981] 1 All ER 257 .

O'Brien $v$ Cunard SS Co [Mass 1891] 28 NE 266.

11 Family Law Reform Act 1969 s8(1).

12 Templeman LJ. Re B (a minor) [1981] I WLR 1421

13 Reid LJ. S $v$ S [1970] 3 All ER 107.

14 Wood J. T $v$ T [1988] Fam 52, [1988] I All ER 613.

15 Re F [1989] 2 WLR 1063.

16 Regg PDG. Law, ethics and medicine. Oxford: Clarendon Press, 1984:95.

16a Bewley S, Libetta C. Medical student examination under anaesthesia should not be performed without explicit consent. Proceedings of the 26th British Congress of Obstetrics and Gynaecology, Manchester, 1992 (in press).

17 Informed consent. Women in Medicine 1986 May:8.

18 Robinson J. Are we teaching students that patients don't matter? f Med Ethics 1985;11:15-21.

19 Chamberlain G, Orr C, eds. How to avoid medicolegal problems in obstetrics and gynaecology. London: Chameleon Press, 1990:16.

20 Corbett J. Second thoughts on the unfortunate experiment. Metro 1990 July:54-73, Sep:124-36. (Discussions about the Cartwright inquiry into unethical practices at Auckland Women's Hospital, New Zealand.)

(Accepted 20 January 1992)

\section{ANY QUESTIONS}

Is it necessary to alter the maintenance dose of warfarin during an acute gastrointestinal infection?

Warfarin is normally rapidly and completely absorbed after oral administration, and complete bioavailability has been shown even in patients with extensive ileal resection. Though warfarin might possibly be incompletely absorbed in acute gastrointestinal infection, this would probably be offset by an increased responsiveness to warfarin associated with acute infections or fever. Because of these competing variables and the unpredictability of the change it would be more sensible to monitor the international normalised ratio frequently and to adjust the oral dose accordingly. When patients are unable to take oral drugs the intravenous route is preferable, but unfortunately warfarin is not available by this route in the United Kingdom. Thus if loss of efficacy did seem likely in a patient, heparin by intravenous infusion might be required until oral warfarin could be reintroduced. $-\mathrm{P} A$ ROUTLEDGE, consultant physician and professor of clinical pharmacology, Cardiff

1 Kearns PR, O'Reilly RA. Bioavailability of warfarin in a patient with severe short bowel syndrome. Fournal of Parenteral and Enteral Nutrition 1981;10:100-1.

2 Loeliger EA, Van der Esch B, Maltern MJ, Hemker HC. Biological disappearance rate of prothrombin factors.VII, IX and $\mathrm{X}$ from plasma in hypothyroidism, hyperthyroidism and during fever. Thrombosis Diathesis Haemorrhagica 1964;10:267-77. 